\title{
Epilogue \\ In Search of an Identity: Landscape Archaeology for Post-Classical Studies Defining and Understanding Archaeological Landscapes
}

\author{
Cristina Corsi \\ Department of Humanities, University of Cassino, Italy \\ email: c.corsi@unicas.it
}

Over the course of the last several decades, landscape archaeology has achieved the status of a discipline in itself, with clearly defined parameters, established methodologies and instruments of research. Nonetheless, that which can also be termed as 'the archaeology of landscapes' covers numerous fields, ranging from geographical to social space, and from physical and environmental aspects to the symbolic significance of places (David \& Thomas, 2008: 19). This great diversity and variety of contents and approaches probably stems from the fact that the concept of landscape is charged with innumerable meanings with virtually impressionistic or speculative definitions that have resulted in a remarkable assortment of approaches.

To start, it is interesting to examine how the definition, interpretation and role of landscape in our culture have evolved, starting from the sixteenth century, when, in the western world, the notion of landscape was "inextricably bound into notions of power and status" (Robertson \& Richards, 2003: 1). The eighteenth century was ruled by landscape design and painting. Landscapes, mainly natural but also those shaped by man, were often represented through the lens of the prevailing romanticism, and in such a way that even contemporary views and perceptions were nuanced with the romantic feeling of landscapes as pictorial (Aurand, 2006: X). More recently, this aesthetic approach has been enriched and imbued with immanent symbolism and ideology. The concept of 'ideological space' can be very easily applied to townscapes, where the surrounding built environment can be intended as "an ideolo- gy about the correct way of living a life, and that ideology involved more than just building a town, but also locating daily activities within it, making it part of the unquestioned mental map of people dwelling there" (Revell, 2008: 43; cf Keay, 1997: 203-204). When it comes to settlement dynamics, this means that landscape organisation had an immanent ideological dimension, and from the way that settlements are displayed and from their architectural shape it is clear that there was an underlying ideology (Metzler et al, 1995).

A more anthropological approach has caused landscape to be viewed as the result of "the practice of transforming land into landscape, [which] began when the first caveman/woman placed a rock carefully or scratched a tree on a wall" (Robertson \& Richards, 2003: 1). Indeed, the fertile encounter between archaeology and anthropology has brought about the awareness that cultural landscapes have to be tackled in a more problematic way, and they have to be considered not as an outcome, but as a process in which nature and culture are two aspects of the same dynamic (Tilley, 1994). The key issue is the perception of the landscape itself; from a phenomenological stance, landscapes can be described as the way in which people experience and understand the world (Robertson \& Richards, 2003: 7).

Within this framework, the concept of 'taskscape', as elaborated by Tim Ingold, is intended as a socially constructed space of human activity, perceived with spatial boundaries and delimitations. The concept stresses the notion that landscape is the space where people perform their daily activities, thus constructing a cultural 
knowledge of it (Ingold, 1993). This perspective has been implemented by Eric Hirsch (Hirsch, 1995: 8). In his interpretation, the definition of landscape as a 'representational reading' of the surrounding space is enriched with a more geographical approach, whereby landscape is considered "a cultural process that brings together the cultural meaning of landscape with the concrete actuality of everyday life" (Hirsch, 1995: 3).

This process has paralleled the advancement of historical geography, in which new perspectives and theoretical frameworks have been adopted. This discipline has also steered its interest towards processes rather than outcomes and as a result, man has become a more active agent of the transformations and a more active than passive subject. Concepts such as 'attitude' and 'ideology' have rooted themselves in the interpretation of landscapes as 'artefacts' (see e.g. Barker, 1979: 561 for an example of a more traditional approach).

The outcome of these intersected perspectives is that landscapes can be studied as physical, ideological, social and cultural objectives of our research. Furthermore, we can study the ways in which landscapes are represented once we individuate the values, meanings and symbols that we attach to them (Robertson \& Richards, 2003: 2). In this context, the understanding and decoding of landscapes is done from a subjective point of view, whilst with the more traditional approach, the aim of historical landscape analysis was to grasp the evolution in features bearing traces of the shapes imprinted by physical and cultural actions (Robertson \& Richards, 2003: 2; cf Sauer, 1925).

\section{Landscape Archaeologies: Multifaceted Approaches to the Time-Space Relation- ship}

This multiplicity of protean definitions of landscape and interpretations of the way in which mankind has related and interacted with it, has resulted in a composite framework. Over the past 40 years, diversified approaches to landscape archaeology have developed from the theoretical as well as from the methodological point of view within this framework. Scholarship was engaged first with the archaeology of settlement patterns (Chang, 1972: 1-26) which was soon framed into the "spatial archaeology" outlined by D. Clarke (1977). The breakthrough of ICTs and digital processing generated a dramatic proliferation of GIS applications and the transposition of statistical spatial models from contemporary geography, economics, architecture and ethology, even though several theoreticians underlined the peculiarities of the analysis of past human behaviour, from the micro to the semi-micro and macro scales of aggregation. As Clarke himself stressed, in this type of paradigm of the discipline, "the retrieval of archaeological information from various kinds of spatial relationship is a central aspect of the international discipline of archaeology and a major part of the theory of that discipline wherever it is practiced" (Clarke, 1977: 1). This approach soon revealed its limits, with respect to the extreme technicalities of the landscapes investigated as mere spaces, "devoid of meaningful places and meaningful emplacement, just as they are devoid of social experience and salience" (McNiven, David \& Barker, 2006: 14).

New developments in the discipline brought a shift in focus from the settlement patterns to the settlement systems, in such a way that a new interest and innovative theoretical speculation about the use and the meaning of landscapes to the people who inhabited them arose (Social Landscapes studies: see, e.g. David \& Thomas, 2008: 32-38). This tenet was rooted in a reaction to or a rejection of the overwhelming importance attributed to survey data. Indeed, plotting some dots on a map has been mistaken for practising landscape archaeology. Instead, our goal should be "to reconstruct people's experience in the landscape", thus performing a "major interpretative operation" (Finlayson \& Dennis, 2002: 225-26). This operation can be described as the contextualisation of the widest range of information and data, retrieved within the framework of an interdisciplinary team covering areas such as geomorphology, botany, historical documentation, ethnography, and remote sensing (Given, 2004: 20). 
Context, complexity and interdisciplinarity are the keywords to delineate the most recent developments, as landscape has been considered as "a dynamic context of different transformations intelligible through time: cultural, historic, political, social, geomorphologic, geographic, anthropological" (Forte, 2005: 213) for which multi- and interdisciplinary approaches need to be adopted and a wide array of detection techniques need to be deployed, involving - among others - cultural, palaeo-environmental, anthropological and geomorphological studies, with all of them governed by advanced digital technologies.

Most remarkably, thanks mainly to contamination with the tenets of anthropology that primarily occurred in Anglo-Saxon scholarship, landscape archaeology acquired a cognitive dimension which removed the focus from the more materialistic themes of research (such as land use, resources exploitation management, production and trades) to an interest in the social, "emotional and spiritual" aspects of the interaction between man and environment (Renfrew \& Bahn, 2000: 398-99). This shift is considered an outcome of the spreading of post-processual paradigms with the result that "the landscape and its monuments are seen not simply as reflecting the social structures of society but, by bringing into being new perceptions about the human place in the world, as facilitating the emergence of a new social order" (Renfrew \& Bahn, 2000: 398-99, for a list of reference see $p$. 603).

Towards the turn of the millennium, a post-processual approach to landscapes as "socially constructed spaces, constitutive of social relations" rather than a passive "backdrop for action" (Robin \& Rothschild, 2002: 161) broke in (Hincks \& McAtackney, 2007: 13-14), paralleled with the more empirical and traditional approaches nursed in the British tradition of local studies (Aston, 1985).

In some schools with a long tradition of field survey, it has been necessary to discuss affinities and differences with the old-fashioned approaches of what was, and still is, termed 'ancient topography', a discipline for which, in turn, it had been necessary to state the conceptual and theoretical differences in respect to historical geography (Castagnoli, Mansuelli \& Alfieri, 1957; see section XXX in this volume). In this more traditional interpretation, the study of territories and settlement patterns in post-classical phases has found fertile grounds, mainly in southern Europe, where most work in landscape archaeology adopted a geographical-historical approach (Corsi, in press a).

In spite of the advancements in field survey and excavation techniques, the developments in several types of material provenance identification and dating, the spectacular progression achieved in the fields of remote sensing, geophysical survey and visualisation tools, and the rise in sophisticated technological advancements with increasingly reliable results (Vermeulen \& Corsi, 2015: 156-57), developments have been uneven across Europe.

The so-called 'New Archaeology' spread rapidly in the Anglo-Saxon world, finding echoes in countries traditionally more open to external stimuli, such as the Netherlands. The introduction of new survey methods promoted by Anglo-Saxon archaeological activities in the Mediterranean, however, generated a fast adoption of the new methodologies and approaches all over the Western world (Wallace-Hadrill, 1991: XI. For a short review of the state of the art until the 1970s in Germany, Great Britain, USA, France and Russia, see Clark, 1977: 5-9. For a brief comment about Byzantine Landscape Archaeology in Greece see Tsigonaki \& Sarris in this volume). The focus shifted from monumental aspects to social, economic, political and cultural factors, and special attention was paid to the relationships between town and countryside (Corsi, in press b).

It is therefore incorrect to state that in Mediterranean countries "art historical approaches in archaeology, compounded with the strength of academic boundaries in other disciplines have mitigated against the development of an approach to landscape analysis and demographic modelling that by definition demands an inter-disciplinary framework linking the natural and social sciences" (Barker \& Mattingly, 1999: III). On the other hand, it is undoubtedly true that the newest trends in 
landscape archaeology filtered very slowly into the study of post-classical landscapes and that innovation in theoretical speculation and methodological debate can only be episodically intercepted in medieval landscape studies (Corsi, in press a).

At the same time, in addition to the effects of the contamination with anthropology previously discussed, mainly continental European archaeologists were engaged in testing the disciplinary boundaries (Hincks \& McAtackney, 2007: 13-14) and were extending their interests to the more traditional fields of geography, natural and earth sciences (Layton \& Ucko, 1999: 15). The 1990s saw the spread of geoarchaeology (De Dapper \& Vermeulen, 2000; Fouache, 2013) and its many variations. Geoarchaeology can be paralleled with environmental archaeology but its origin is alien to new processual paradigms. Although not many projects in medieval landscapes adopted this methodology, a few examples can be listed. In most of these cases, however, the stress still remains on sociocultural factors rather than on those of an environmental nature (Corsi, in press a).

These excursions into the earth and natural sciences renewed substantially studies in demographic trends, which still kept the essential contributions by historical and social scholarship, and stimulated the adoption of the perspective of the longue durée. By bridging the gap between the humanities and hard sciences with the adoption of the widest array of techniques and instruments of research, it has been possible to determine and visualise long term demographic changes in both rural and urban contexts, thus providing new insight into the history of mankind and man's interaction with the natural environment (Barker \& Mattingly, 1999: III). Finally, this radical change in the approach to landscape studies has been very favourable to post-classical studies, where a few seminal projects, like the South Etruria Survey started by the British School at Rome, opened the way to numerous enterprises focussed on the reconstruction of demographic trends from the longue durée perspective (see Patterson, 2010 : 143-44).
In summary, we could say that the reasons behind the attractiveness of landscape archaeology in contemporary scholarship probably lie principally in this vibrant diversification of paradigms, tenets, practices and methodologies, as well as in the fact that after decades of sometimes fierce debate, landscape archaeologists reached an agreement on the lack of agreement and consistency of the set of objectives and approaches (David \& Thomas, 2008: 25). There are, of course, already many shared aims among the different interpretations of landscape archaeology:

“they employ a range of (mainly non-intrusive) methods, operate at multiple scales of analysis and seek to move beyond a focus upon apparently bounded entities like monument or "sites". Our point of departure [...] is that diversity - of methods, field location, disciplinary influences and contemporary voices - is a principal characteristic of Landscape Archaeology (Hincks \& McAtackney, 2007: 14)".

\section{A "Wind of Change" in Post-Classical Landscape Studies?}

In the session entitled The wind of change: town, country, land-use and settlement patterns between the fourth and the seventh century $A D$, speakers were invited to present the newest data about settlement patterns in a wide array of geographical contexts during the four centuries of incubation of the changes that would announce the new world of Medieval Europe. The time span that we delimited is probably the first choice that we need to explain. Without delving into the intricacies of a discussion that is still open and that has to accept the diverse opinions of individual scholars and orientations of structured scholarships, we can say that we did consider the fourth century as the threshold of Late Antiquity, even if for the fourth and the first part of the fifth century the definition of Late Roman or Late Imperial is preferable. The lower limit of the time range has been fixed at the seventh century, as the seventh century can be consid- 
ered the borderline between Late Antiquity and the Early Middle Ages. Obviously, this delimitation cannot take into account the peculiarities of geohistorical compartments, but just one of the most appreciable results of the session was the fact that we could compare synchronic historical trends in very different regions. From Atlantic Lusitania to the Ural mountain range, down south until Sicily and the Anatolian coast, a spectacular overview of case studies adopting different methodologies and targeting different goals, has materialised before our eyes.

Contributors were asked to present regional case studies in light of the newest acquisitions in our knowledge on trade and productions and, with support of the geosciences, on changes in ecological conditions. Our intention was to focus the discussion on topics such as the relationship between town and country, settlement patterns, the transformations in land use and communication networks, different forms of land division and reclamation or water regimentation activities attributable to Late Antiquity and the Early Middle Ages.

We were pleased by the large number of proposals, from which we selected those that appeared to cover the widest range of fields and approaches. With respect to the newest knowledge in the discipline, different examples of diachronic investigations, such as those on Crete (C. Tsigonaki \& A. Sarris) and in the Contessa Entellina region in Sicily (A. Facella), were presented. Pertaining to the latter, we would like to stress how the presentation of the most significant issues concerning pottery distribution and interpretation of rural sites goes beyond the traditional diachronic presentation of site numbers and distributions and extends to the transformations detected in the distribution of certain categories of finds. The paper points out some biases in the survey data and enlightens some methodological issues.

Also, the paper by C. Tsigonaki and A. Sarris dwells on the disputable matter of the definition of functions and typology of settlements. The snapshot we have of Early Byzantine Crete is a composite picture and a noteworthy example of a wide spectrum research project that aims to exploit every type of source without neglecting the most traditional ones such as written texts, epigraphical documents and any kind of legacy data. The GIS data processing eventually allows sophisticated spatial analysis and interesting studies of the network system. The geographical perspective, however, is balanced by the introduction of more social and historical factor analyses which explore the nature of the relationship between man and space, thus humanising the relational processing.

The above mentioned spatial approach also characterises the contribution of Dmitry Korobov who defines the introduction of GIS processing in archaeology as one of the most influential events in landscape archaeology, marked by the adoption of spatial GIS modelling. In this pioneering work on the Northern Caucasus, the methodology of data processing acquires a central role, paralleled with the identification and classification of the settlement typology. The processing of a large amount of new and legacy data, integrated with palaeo-environmental studies, has allowed light to be shed on the Alanic settlement patterns over the course of time. As a result, it has extended our understanding to now include geographical, historical, economic cultural, social and anthropological factors.

As anticipated,

“landscape can also be understood as an aggregation of resources, affording both opportunities and limitation for human development. In this strand of Landscape Archaeology, it is the spatial relationship among people, soils, raw materials, and water sources that demand attention (David \& Thomas, 2008: 25)".

This approach has been applied to landscapes mainly concerning pastoralism and transhumance, for mineral exploitation and metal mining at the end of the Middle Ages and the beginning of the Modern Age. Here we can present a very interesting example of the study of sulphur mining (L. Zambito). In spite of the difficulties of collecting in- 
formation about the earliest phases of these activities and of the problematic dating of the traces left by mining, 'minescapes' can be identified as some of the most interesting contexts where human and natural action interact heavily. The importance of minescapes is connected to the challenging condition of instability (termed as “liquidity” by L. Zambitol due to the continuity of use through time and the conservatism of exploitation techniques. Again, the socio-economic transformations that seem to have taken place between the fourth and the sixth centuries, with the clustering of sparse settlements into a village and the casting down of the town of Agrigento's role as fiscal centre for these activities (while its role as hub for trade seems to last until the beginning of the ninth centuryl, are magnified when investigated by means of an approach that uses environmental and spatial data to design the historical processes and build a narrative.

Issues related to the transformation of urban space and the suburbs, as well as the dynamics of expansion, reduction or abandonment of towns were addressed in the paper by V. Cassiani and V. lacomi and were well integrated into the broader evaluation of the surrounding landscape and catchment areas. Here the perspective is orientated mainly towards the economic implications and the territorial fallouts of production activities and trades. At the same time, some transformations of the inhabited space are read from the perspective of symbolic-ideological parameters, stretching the interpretation of material elements to the immaterial aspects of perception of the surrounding landscape (supra).

To this topic of town and country relationships, we can connect the two papers from our collection that discuss the phenomenon of Christianisation of urban and suburban landscapes in central Lusitania (E. Gallo) and Italy (A. Luciano). Italian scholarship, like Spanish and French, has a long tradition in this approach and as is proven here, the study of Christian topography is progressively enriched by new data coming from excavations carried out in deserted towns as well as in those that endured continuous occupation. The two Portuguese case studies and the many examples from Italy show how immaterial factors like religion and worship influenced the material aspects of settlements with the emergence of preferred paths lurban or suburban), the development or the shrinking of specific areas, the increasingly frequent piercing of the city walls in connection with suburban sanctuaries and the changes in polarisation of urban assets following the construction of cathedrals or important churches.

Many contributions in post-classical landscape archaeology rely upon data from traditional urban excavations. The paper by F. Redi, therefore, provides us the occasion to analyse how the study of towns in Late Antiquity and the Early Middle Ages has removed itself from the more traditional historical approach largely based on written sources and is shifting toward a stand-alone urban archaeology which is only partially rooted in urban historical geography.

The archaeology of towns during these transitional phases has engaged several generations of archaeologists. Far from being closed, a thirty year long and articulated debate has shown that many parameters have to be taken into account when analysing the evolution and transformation of classical towns. Archaeology has indirectly inherited the approaches of both urban history and urban geography, aiming at the study of the humanistic and functional elements comprising the urban scene (Dyos, 1973: 25). If it is true that "history is about chaps, geography about maps", then urban archaeology deals "with urban life and townspeople and their formal and informal institutions" as it is "concerned with patterning and spatial distribution" (Carter, 1983: XIV).

The newest trends and paradigms of environmental and geoarchaeology, characterised by the entry of earth and natural sciences into the domain of humanities and geohistorical disciplines, have inspired several of the contributions collected here. The townscape of Byzantine Caričin Grad, an artificial imperial city archaeologically frozen in the short time span between its foundation and its abandonment, is not analysed here in its spatial connotations, but in its social and economic fea- 
tures as revealed by the botanical and zoological finds ( $C$. Röhl et al in this volume). In the attempt to study 'Households, consumption and everyday life', aspects of production and consumption are investigated in relation to activity zones; "taskscapes" are here intended more in their economic and environmental than in their anthropological reading (supra).

The latter reading is central in the paper by $C$. Bassi \& V. Amoretti, where osteological analyses of human and animal remains prove that many individuals of the human group buried in San Cassiano were engaged in craftsmanship related to the wool production cycle. Additional social features can be brought to light by studying the gender and age parameters and the markers of osteological stress, pointing in this case to horse riding activities of a group of men with a possible familial link and showing interpersonal violence that occurred among other individuals. It is noteworthy that by crossing data derived from archaeological and physical anthropological studies, we are able to infer social and even ethnic changes in the structuring of society and transformations that are typical of this transitional era.

Indeed, the use of human skeletal remains in landscape archaeology has been increasingly significant (Pate, 2008, with broad reference list). Human bones can be considered as archives retaining important information concerning the use of past landscapes by human populations. As human remains retain traces of the physical, chemical, climatological and societal environments in which they lived, the analysis of human skeletal remains produces valuable spatio-temporal information and can contribute substantially 'to an improved understanding of past human relationships within and between various natural and cultural environments' (Pate, 2008: 502). Apart from the obvious inferences about diet, health and the main economic activities (sedentary, nomadic, agricultural versus hunter-gatherer lifestyles, strenuous productive activities, etc.), the skeletal remains, when available in an ample and well-distributed sampling, provide information about age, gender and social groups. Cemeteries are a principal test ground for detection of social organisation and complexity. In this way, as stressed above, anthropological study concurs in understanding the history of economy versus landscape and adds a holistic component to landscape archaeology.

\section{Epilogue}

The geographical and methodological heterogeneity of the contributions that we have assembled here could be 'disturbing' for those who advocate for a greater uniformity of purposes, methodologies and practices with the prime goal of achieving a standardisation of procedures that would facilitate comparative research (Barker \& Mattingly, 1999: IV; Anschuetz, Wilshusen \& Scheick, 2001: 157). Contrary to this, these proceedings demonstrate the great variety of approaches and offer an open assessment of the results achieved so far. This diversity in starting and ending points suggests an extraordinary richness for the future of the discipline, in which post-classical studies will finally find their acknowledgement and will further shape their identity.

\section{References}

Anschuet KF, RH Wilshusen \& CL Scheick 2001: An archaeology of Landscape: Perspectives and directions, Journal Archaeological Research, 9(2), 157-211.

Ashton M \& T Rowley 1974: Landscape Archaeology: An Introduction to Fieldwork Techniques on Post-Roman Landscapes, David and Charles, Newtown Abbot.

Aston M, 1985: Interpreting the Landscape, Batsford, London.

Aurand M, 2006: The Spectator and the Topographical City, University of Pittsburgh Press, Pittsburg.

Barker ARH, 1979: Historical geography: A new beginning?, Progress in Human Geography, 3(4), 560-70.

Barker G \& D Mattingly 1999: “General Editors” Introduction: The POPULUS Project', in Leveau Ph, Walsh $K$ \& Trément $F$ (ed.), Environmental reconstruction 
in Mediterranean landscape archaeology: I-VII, Oxford Books, Oxbow.

Carter H, 1983: An introduction to Urban Historical Geography, Caulfield East/ Edward Arnold, London/ Baltimore.

Castagnoli F, GA Mansuelli \& N Alfieri 1957: Geografia e topografia storica, in Enciclopedia Classica, 3, 10, vol. 3-4: 223-38. Società editrice internazionale, Turin.

Chang KC, 1972: Settlement Patterns in Archaeology (Addison Wesley Modular Publications, Module in Anthropology 24), Addison-Wesley Pub. Co., Reading, MS.

Clarke DL, 1977: Spatial Information in Archaeology, in Clarke DL, Spatial Archaeology: 1-32. Academic Press, Boston.

Corsi C, (in press a): Medieval landscape archaeology and landscapes of medieval archaeology in Italy. A review, Medieval Archaeology 60, 2 (2016) laccepted June 2015).

Corsi C, (in press b): Understanding the town-territory relationship: Theoretical frameworks, methodological issues and the devilish dog. A case-study from Lusitania, in: Poblome J, Vermeulen F, Claeys J \& Taelman D (ed.), The space between: current investigations into Roman suburbia" (Journal Roman Archaeology, Supplement).

David B \& J Thomas 2008: Landscape Archaeology: Introduction, in David B \& Thomas J (ed.), Handbook of Landscape Archaeology: 27-43. Left Coast Press, Walnut Creek.

De Dapper M \& F Vermeulen (ed.) 2000: Geoarchaeology of the landscapes of classical antiquity, Peeters, Leuven.

Dyos HJ 1973: Urbanity and Suburbanity. Leicester Academy Press, Leicester.

Finlayson B \& S Dennis 2002: Landscape, archaeology and heritage, Levant, 34, 219-27.

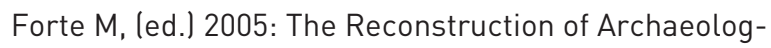
ical Landscapes through Digital Technologies. Proceedings of the 2nd Italy-United States Workshop. Rome, Italy, November 3-5, 2003, Berkeley, USA, May 2005, Archeopress, Oxford.

Fouache E, 2013: The Geoarchaeological Approach, in Corsi C, Slapšak B \& Vermeulen F (ed.), Good Practice in Archaeological Diagnostics. Non-invasive Survey of Complex Archaeological Sites: 245-52.
Springer, Cham/Heidelberg/New York/Dordrecht/ London.

Given M, 2004: The Archaeology of the Colonised, Routledge, London/New York.

Hincks D \& L McAtackney 2007, Introduction. Landscapes as Standpoints', in Hincks D, McAtackney L \& Fairclough $\mathrm{G}$ (ed.), Envisioning Landscapes. Situations and Standpoints in Archaeology and Heritage: 13-29. Left Coast Press, Walnut Creek.

Hirsch E, 1995: Landscape between space and place, in Hirsch E \& O'Hanlon M (ed.), The Anthropology of Landscape: Perspectives on Place and Space: 1-30. Clarendon Press, Oxford.

Ingold T, 1993: The Temporality of Landscape, World Archaeology, 25(2), 152-74.

Keay SJ, 1997: Urban transformation and cultural change, in Díaz-Andreu M \& Keay SJ (ed.), The archaeology of Iberia: the dynamics of change: 192210. Routledge, London/New York.

Layton R \& P Ucko (ed.) 1999: The Archaeology and Anthropology of Landscape: Shaping Your Landscape (One World Archaeology), Left Coast Press, Walnut Creek.

McNiven IJ, B David \& B Barker 2006: The Social Archaeology of Indigenous Australia, in David B, Barker B \& McNiven IJ (ed.), The Social Archaeology of Australian Indigenous Societies: 2-19. Aboriginal Studies Press, Canberra.

Metzler J, M Millett, N Roymans \& J Softra (ed.) 1995: Integration in the early Roman west: the role of culture and ideology. Papers arising from the international conference at the Titelberg (Luxembourg), 12-13 November, 1993. International Conference "The Romanisation of the Early Roman West" (1993, Luxembourg, Luxembourg). Musée national d'histoire et d'art, Luxembourg.

Pate FD, 2008. The Use of Human Skeletal Remains in Landscape Archaeology, in David B \& Thomas J (ed.), Handbook of Landscape Archaeology: 502-20. Left Coast Press, Walnut Creek.

Patterson H, 2010: Rural settlement and economy in the middle Tiber Valley: AD 300-1000, Archeologia Medievale, 37, 143-61.

Renfrew C \& P Bahn 2000: Archaeology: Theories Methods and Practice, 3rd edn, Thames \& Hudson, London 
Revell L, 2008: Roman imperialism and local identities, Cambridge University Press, New York.

Robertson I \& P Richards 2003: Introduction, in Robertson I \& Richards P (ed.), Studying Cultural Landscapes: 1-18. Hodder Arnold, London.

Robin C \& NA Rothschild 2002: Archaeological Ethnographies: Social Dynamics of Outdoor Space, Journal of Social Archaeology, 2(2): 159-72.

Sauer C0, 1925: The morphology of landscape, University of California Publications in Geography, 2(2): 19-53.

Tilley C, 1994: A Phenomenology of Landscape. Place, Paths and Monuments, Berg, Oxford.

Vermeulen F \& C Corsi 2015: Some Methodological Considerations and Suggestions for Good Practice in Diagnostics and Visualisations of Complex Archaeological Sites: the experience of the Radio-Past project, in Traviglia A (ed.), Across Space and Time. Selected Papers from the 41st Computer Applications and Quantitative Methods in Archaeology Conference (Perth, WA, 25-28 March 2013): 156-65. University Press, Amsterdam.

Wallace-Hadrill A, 1991: Introduction, in Rich J \& Wallace-Hadrill $A$ (ed.), City and Country in the Ancient World: IX-XVIII. Routledge, London/New York. 
